Revista Iberoamericana, Vol. LXVIII, Núm. 200, Julio-Septiembre 2002, 765-768

\title{
LA CRISIS DEL CONTRATO MIMÉTICO EN LOS TEXTOS CONTEMPORÁNEOS
}

\author{
POR \\ Ana María Barrenechea \\ Columbia University
}

Algunos críticos proponen la interpretación de la crisis del personaje en la novela como espejo de la crisis de la persona en la sociedad de masas. Esto implica creer que la literatura es un reflejo de la sociedad en que se produce y que tal tipo de relación debe entenderse como nexo causal entre la vida del hombre en la sociedad de masas y la llamada disolución del personaje.

La relación sociedad-obra literaria es muy compleja y podrían ofrecerse otras interpretaciones. Citaré como ejemplo sólo dos entre muchas. Una es la que atiende a la repercusión de los cambios que se han dado en el proceso de producción, comercialización y distribución del libro. Con ello ha variado la imagen que el artista se ha hecho de su función social, su diferente resistencia a ser incluido en una clase ocupacional, los signos o indicios de esa posición en su obra. Otra sería la que recuerda que la quiebra de los códigos y la articulación de nuevos códigos en el arte contemporáneo es paralela a la revolución en la física actual (teoría de la relatividad, teoría cuántica, aceptación de las relaciones de indeterminación), todo lo cual modifica la concepción de los nexos del hombre y la naturaleza.

Por ahora me limitaré a un hecho significativo en el fenómeno literario de nuestro siglo. A todos llama la atención que en la ficción actual ha habido, por una parte, cambios de estructura novelesca que replantean las relaciones literatura-mundo, y por otra, que se ha agudizado la tematización de esas relaciones. Me refiero a la crisis del contrato mimético, que afecta: 1) a los nexos entre obra y referente (relaciones extratextuales); 2) a las interconexiones de los distintos niveles y componentes de la novela (relaciones intratextuales), y 3) al realce del diálogo con otras obras (relaciones intertextuales).

Se han disuelto los componentes tradicionales: escenario, personajes, acciones. También son cada vez más ambiguos los espacios de la enunciación y lo enunciado: narrador, narratario, historia contada. Esta redistribución topológica interna de la obra tiene su paralelo en las entidades externas: disolución de la imagen del escritor, abolición del referente, existencia pura del texto o nueva función del lector como infinito decodificador de la escritura.

Esta ruptura del contrato mimético para un grupo de obras (y de críticos) bloquea el proceso de reconocimiento y de lectura en el que la obra remite al mundo y el mundo a la obra. Entonces se fuerza a leer el texto como un objeto verbal autónomo. 
Para citar a un escritor hispánico embarcado en esta corriente hasta sus extremas consecuencias, recordaré opiniones de Severo Sarduy: ${ }^{1}$

El hombre se adentra en el plano de la literalidad que hasta ahora se había vedado, formulando esa pregunta sobre su propio ser, sobre su humanidad, que es ante todo la del ser de su escritura. (30)

Si lo único seguro que poseen los hombres es el texto que tejen durante su vida, lo único válido de la obra será el texto, y no su supuesta analogía con ese correlato exterior a ella que es "el mundo que nos rodea" (47). Por eso dice, parafraseando a Jean-Louis Baudry, que el texto es una máscara que nos engaña, “ya que si hay máscara no hay nada detrás; superficie que no esconde más que a sí misma, (...) la máscara simula la disimulación para disimular que no es más que disimulación” (48), más adelante insiste: “Nada evoca, ni siquiera para reírse de él, un referente exterior al libro mismo” (49).

Frente a la corriente anterior, cabría otra que mantiene la relación obra-mundo (el texto como mensaje, con un referente y un destinatario externos), repiensa sus conexiones con el contexto en que le toca vivir, se pregunta sobre la función social del arte (y a veces sobre el sentido que tiene ser escritor dentro del circuito de producción y comercialización del libro). No se trata de una vuelta a la novela decimonónica, sino de una obra altamente innovadora que también busca un nuevo lenguaje apropiado a sus interrogantes y también los tematiza. Su replanteo de la relación obra-mundo podría compararse a la concepción de la metáfora como entidad de referencia desdoblada, según Paul Ricoeur. ${ }^{2}$

Cualquiera que lee una metáfora advierte un contrasentido entre la palabra foco y el marco o contexto, si se la toma en sentido literal. El enunciado metafórico obliga a regirse por el concepto de referencia desdoblada, que consiste en "hacer surgir una nueva pertinencia semántica sobre las ruinas del sentido literal” con el poder de reorganizar la visión de las cosas y proponer una redescripción de ellas. La metáfora ofrece simultáneamente una tensión en el enunciado (entre foco y marco), una tensión entre dos interpretaciones: literal (contrasentido) y metafórica (que hace sentido por medio del no sentido), y una tensión (radicada en la cópula expresa o tácita) entre la identidad y la diferencia en el juego de la semejanza” (311).

Planteo, pues, dos tendencias contemporáneas: la que anula el referente y se autoabastece, y la que postula "rabiosamente" un referente, establece una tensión dialéctica con él (identidades y diferencias en el juego de la semejanza), ofreciendo la lucha eterna del texto por producir una metáfora del referente. Se sobrentiende que estas dos corrientes que esbozo son los polos opuestos de un amplio abanico y no una clasificación binaria y maniquea.

Sólo daré dos ejemplos, uno de cada tendencia. De la primera comentaré El hipogeo secreto, de Salvador Elizondo, ${ }^{3}$ y me concentraré en los personajes (y en los narradores, que considero un tipo particular de personaje).

${ }^{1}$ Severo Sarduy, Escrito sobre un cuerpo (Buenos Aires: Sudamericana, 1968). El número de página va entre paréntesis.

${ }^{2}$ Paul Ricoeur, La métaphore vive (Paris: Seuil, 1975).

${ }^{3}$ Salvador Elizondo, El hipogeo secreto (México: Joaquín Mortiz, 1968). 
Se diría que la única diferenciación concreta que El hipogeo secreto ofrece al lector es la de poder clasificarlos como seres masculinos o femeninos. En seguida se destaca la manera de nombrarlos: o con pronombres personales (yo, tú, él, etc.), o con pronombres indefinidos (Alguien, el Otro), o con letras (T, X, E, H), es decir, con signos que son al mismo tiempo móviles (de significación ocasional) y no descriptivos. A veces emplea también nombres propios que son conversión de nombres comunes y conservan, por tanto, una sombra de su capacidad descriptiva (el Imaginado, el Sabelotodo, el Pantokrator, la Perra, Herminester el Exhumado, Meneur inquietante, la Flor de Fuego, Mía, etc.), pero sin la verdadera capacidad de individuación del nombre propio. ${ }^{4}$ Junto a ellos figura el nombre del autor, aparentemente bien individuado pero tan engañoso como los otros, al ponerlo en el mismo nivel que los otros, incluirlo como en cajas chinas en la "vida", "historia", "mundo imaginario" de los otros, y aun desdoblarlo con un pseudo-Elizondo (48-49). El yo, el tú, etc., practican una danza de instancias pronominales, seriales indéxicas que cambian constantemente de referente. Cada vez que aparecen resulta dudosa la atribución a cualquiera de los personajes cuya mínima identidad va intentando elaborar el lector como proyecto factible con el recurso de otros indicios (lugares, acciones, en general predicados). Por su parte, los nombres propios son también incapaces de constituirse en vehículos de identidad: cuando el lector se confía a su función de etiqueta fija — característica del nombre propio—, muy pronto descubre la falacia y empieza a sospechar, de modo nunca seguro, que varios nombres recubren a un solo personaje.

Igual juego ambiguo ocurre con los espacios y con las acciones, repetidas sin correlación temporal y causal. Al notar su recurrencia el lector intenta asociar espacios y acciones a cada personaje construyendo predicados constantes que los individualicen, pero esa sombra de identidad se desvanece también. Tanto las acciones como los espacios tienen una estructura topológica de inclusiones y reversiones, como la tira de Möbius o las cajas chinas, con perspectivas infinitas en abismo.

Como muchas novelas contemporáneas, ésta contiene constantes auto-referencias, muestra internamente el modelo que la origina y además propone interpretaciones que a la vez son múltiples y contradictorias. En una página se dice que el personaje de la novela es la "materialización de un mito cuyo origen está en mi propia vida cotidiana” (54); en otras, que Elizondo tiene la fantasía morbosa de "concebirse a sí mismo y al mundo como un hecho narrado" (55), o que la novela es "una crónica banal”, o que tiene "un fondo secreto de la vida" (37), o que las palabras son los "héroes del libro" (47), entre otras claves posibles (36, 40, 58-60, 99, 149, 159, etc.).

En síntesis, el texto se presenta como una máquina productora que funciona en el vacío, como una agresiva destrucción de la referencialidad por el choque de sus contradicciones. No es ya todo para todos (como le gusta decir a Borges con frase de San Pablo), es un mecanismo que dice infinitamente “Nada para nadie”, sólo la inscripción del grafo.

\footnotetext{
${ }^{4}$ Para un análisis de las categorías gramaticales (nombre común, nombre propio, pronombre, etc.) y sus modos de significación, véase mi artículo "El pronombre y su inclusión en un sistema de categorías semánticas”, en Ana María Barrenechea y Mabel M. de Rosetti, Estudios de gramática estructural (Buenos Aires: Paidós, 1969).
} 
El ejemplo de la otra tendencia que quiero mencionar es El zorro de arriba y el zorro de abajo, de José María Arguedas. ${ }^{5}$ Los zorros tienen, como se recuerda, tres componentes: los “Diarios" del autor, la novela de Chimbote y los diálogos del Zorro de arriba y del Zorro de abajo. El libro es un caso extremo de afirmación del nexo de la obra con el referente, del autor con la obra y con la encrucijada histórica y personal que le tocó vivir. Esto se subraya al incorporar un elemento no fictivo: el diario en que Arguedas expone la crisis que lo lleva al suicidio y el proceso de composición de la novela. Pero el texto se despliega con una libertad imaginativa que permite el paso del estrato mítico de los diálogos entre los zorros a la novela del puerto pesquero (a la vez ficción pseudomimética de la vida de Chimbote y metáfora narrativa del mundo contemporáneo), y de ellos dos a los fragmentos explícitamente autobiográficos sobre su crisis psíquica y la elaboración de la propia novela que los incluye.

Lo que me interesa destacar también es que esta obra se focaliza en el enfrentamiento entre grupos centrales y grupos marginales, sean éstos clases sociales, grupos étnicos o naciones enteras. No es el caso del individuo que pierde su personalidad en la masa, que tanto preocupa a algunos críticos contemporáneos, sino el de entidades étnico-sociales (los indígenas) y una entidad nacional (el Perú), que luchan por conservar su autonomía de decisión y su identidad, sus posibilidades de desarrollo económico-político-cultural con capacidad de elegir el signo que tendrá su futuro.

Ante la crisis del contrato mimético, los escritores pueden inclinarse a la antirreferencialidad o bien decidirse por una suprarreferencialidad que, cuestionando la mímesis novecentista y la confianza que su realismo tenía en las relaciones lenguajeliteratura-mundo, no abandona el diálogo con el referente, sino que lo realza hasta exasperarlo.

Volumen XLVIII

Enero-Junio 1982

Números 118-119

\footnotetext{
${ }^{5}$ José María Arguedas, El zorro de arriba y el zorro de abajo (Buenos Aires: Losada, 1971). Para un comentario más extenso de esta novela, véase mi artículo "Escritor, escritura y materias de las cosas en los Zorros de Arguedas”, en Textos hispanoamericanos. De Sarmiento a Sarduy (Buenos Aires: Monte Avila, 1978), pp. 289-318.
} 